\title{
A single amino acid exchange transfers VP16-induced positive control from the Oct-1 to the Oct-2 homeo domain
}

\author{
Jiann-Shiun Lai, ${ }^{1,2}$ Michele A. Cleary, ${ }^{1,3}$ and Winship Herr ${ }^{1}$ \\ ${ }^{1}$ Cold Spring Harbor Laboratory, Cold Spring Harbor, New York 11724 USA; ${ }^{2}$ Genetics Program and ${ }^{3}$ Department of \\ Molecular Microbiology, State University of New York at Stony Brook, Stony Brook, New York 11794 USA
}

\begin{abstract}
The selective association of the herpesvirus trans-activator VP16 with the human Oct-1 homeo domain is a model for differential positive transcriptional control by homeo domains. VP16 discriminates between the closely related homeo domains of Oct-1 and Oct-2 by distinguishing among their seven amino-acid differences; these differences lie on the surface that is thought to be accessible when the homeo domain is bound to DNA. Only two of these seven differences are recognized by VP16, one in each of the first two $\alpha$-helices of the tri- $\alpha$-helical homeo domain. The major determinant for selective association with VP16 in vitro and VP16-induced positive control in vivo is a single glutamic acid residue at position 22 in the first $\alpha$-helix of the Oct-1 homeo domain, but the acidic properties of this residue are not critical for association with VP16 in vitro or in vivo, because it can be replaced by glutamine with little or no deleterious effect. Mere replacement of the single corresponding alanine residue in the Oct-2 homeo domain with the key glutamic acid residue is sufficient to confer on the Oct-2 homeo domain the ability to associate with VP16 in vitro and respond to VP16-induced positive control in vivo. Thus, the specificity of homeo domain positive control can be conferred by a single amino acid difference.
\end{abstract}

[Key Words: Transcription; herpesvirus; POU domain; protein-DNA complexes; protein-protein interaction]

Received August 28, 1992; revised version accepted September xx, 1992.

The 60-amino-acid homeo domain is a critical determinant of the regulatory capacity of homeo domain proteins (for review, see Hayashi and Scott 1990). Its transcriptional regulatory specificity, however, cannot be fully explained by its DNA-binding specificity. Selective interactions with regulatory cofactors are likely to be additional key determinants of homeo domain specificity, although the manner by which such specificity is achieved is not precisely known.

An example of selective homeo domain-cofactor interaction is the differential ability of the closely related homeo domains of the human POU proteins Oct-1 and Oct- 2 to associate in a multiprotein-DNA complex with the herpes simplex virus (HSV) trans-activator VP16 (Stern et al. 1989; Katan et al. 1990; Kristie and Sharp 1990; Stern and Herr 1991). Oct-1 and Oct-2 are members of the POU family of homeo domain proteins in which a POU-specific region together with the homeo domain form a bipartite DNA-binding domain called the POU domain (Herr et al. 1988; Sturm and Herr 1988). The POU domains of Oct- 1 and Oct- 2 are very similar and display similar, if not identical, DNA-binding properties (Staudt et al. 1986; Aurora and Herr 1992). VP16 (also called Vmw65 and $\alpha$-TIF) selectively associates with Oct-1 by distinguishing among seven Oct-1 and Oct-2 homeo domain differences that are thought to be accessible when Oct-1 or Oct- 2 is bound to DNA /Stern et al. 1989). This selective association exemplifies one mechanism by which proteins that display the same DNA-binding specificity, such as Oct-1 and Oct-2, can differentially regulate transcription (for review, see Herr 1992).

The homeo domain is a tri- $\alpha$-helical structure belonging to the helix-turn-helix superfamily of DNA-binding domains. The helix-turn-helix superfamily includes the DNA-binding domains of prokaryotic transcriptional regulators such as that of $\lambda$ repressor (for review, see Pabo and Sauer 1992). The precise structure of the Oct-1 homeo domain is not known, but it is likely to be very similar to that of other homeo domains /see Wolberger et al. 1991). Figure 1 shows the position and identity of the seven differences between the Oct-1 and Oct-2 homeo domains superimposed on a diagram of the engrailed homeo domain bound to DNA (Kissinger et al. 1990). Two of the seven Oct-1 and Oct-2 homeo domain differences (the two positions in helix 2 marked by asterisks in Fig. 1) lie in positions analogous to the sites of positive control mutations in the $\lambda$ repressor. In the $\lambda$ repressor, positive control mutations lie within the DNA-binding domain and disrupt its ability to activate expression of its own gene but have little, if any, effect on DNA binding (Guarente et al. 1982; Hawley and McClure 1983; Hochschild et al. 1983). Similar types of DNA-binding domain mutations in eukaryotic transcriptional regula- 


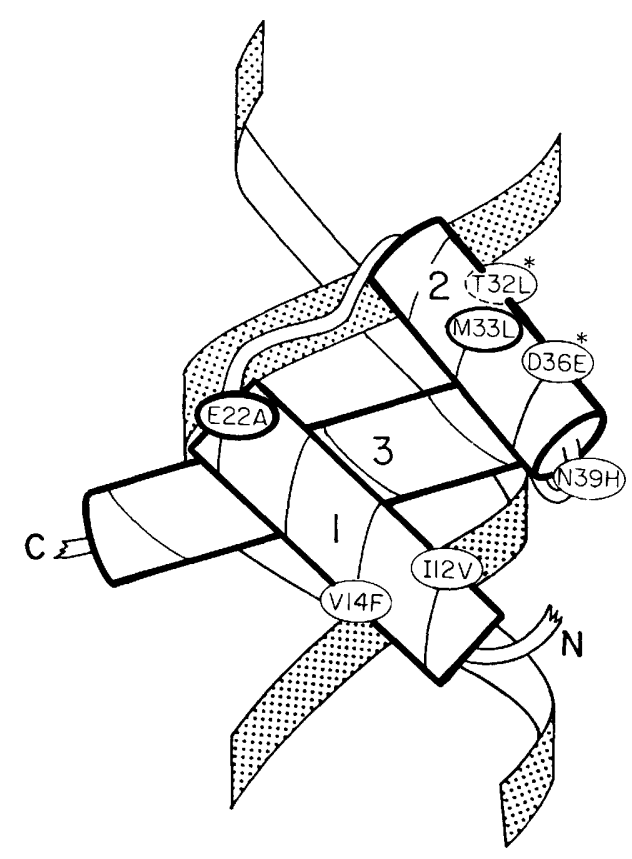

Figure 1. The positions and identities of Oct-1 amino acids that differ from the Oct-2 homeo domain are indicated on an illustration of the engrailed homeo domain bound to the major groove of DNA (stippled) [adapted from Kissinger et al. (1990)]. The three homeo domain $\alpha$-helices $(1-3)$ are drawn as bold cylinders. The seven amino-acid differences between Oct-1 and Oct- 2 homeo domains are circled. The identities and positions of Oct- 1 residues are indicated followed by the identities of the amino acids in the Oct- 2 homeo domain at the corresponding positions. The amino acids are numbered according to the convention used by Kissinger et al. (1990). The asterisks (*) identify the homologous positions of positive control mutations in the $\lambda$ repressor (Hochschild et al. 1983). (N) amino terminus; (C) carboxyl terminus.

tors have also been referred to as positive control mutations (Schena et al. 1989; Stern et al. 1989). As in the $\lambda$ repressor, one or more residues involved in association with VP16, and, hence, probably positive control, lie within helix 2, although Oct-1 residues outside of helix 2 are also involved in VP16 association (Stern et al. 1989).

Here, we identify the individual contribution of each of the seven amino-acid differences between the Oct-1 and Oct-2 homeo domains for selective association with VP16 in vitro. The results show that a single glutamic acid for alanine difference in helix 1 is the key determinant by which VP16 discriminates between the Oct-1 and Oct- 2 homeo domains. Transfer of this single amino acid to the Oct-2 homeo domain is sufficient to support VP16-induced complex formation in vitro and VP16-induced positive control in vivo.

\section{Results}

A single glutamic acid residue is the key determinant for selective association of the Oct-1 homeo domain with VP16

To identify which of the seven differences between the Oct-1 and Oct-2 homeo domains are responsible for the differential ability of Oct- 1 and Oct- 2 to associate with VP16, we individually exchanged each of the seven amino-acids in the Oct-1 homeo domain for its Oct-2 counterpart, as indicated in Figure 1, and assayed its effect on association with VP16. We refer to the amino acid exchanges by the single-letter code and position of the wild-type residue followed by the single-letter code of the replacing amino acid. Thus, in the E22A exchange the glutamic acid residue at position 22 of the Oct-1 homeo domain has been replaced by the Oct-2-derived alanine residue at this position. VP16-induced complex formation was assayed by electrophoretic mobility retardation with VP16 and an auxiliary host cell factor called HCF, C1, VCAF, or CCF /Gerster and Roeder 1988; Kristie et al. 1989; Katan et al. 1990; Xiao and Capone 1990; Stern and Herr 1991) on a probe from the HSV ICP0 promoter /Gerster and Roeder 1988; Stern and Herr 1991) containing the cis-acting target of VP16 activation, the TAATGARAT ( $\mathrm{R}=$ purine) motif. This TAATGARAT site contains an overlapping octamer motif, which serves as a binding site for Oct-1 and Oct- 2 in the absence of VP16 and which we refer to as an IOCTA $^{+}$|TAATGARAT site. The auxiliary host cell factor (HCF) stimulates VP16-induced complex formation and is a component of the VP16-induced complex, but VP16 is responsible for discriminating between the Oct-1 and Oct-2 homeo domains (Stern and Herr 1991; Pomerantz et al. this issue).

Figure 2 shows the result of an assay for DNA binding and VP16 association with the variant Oct-1 POU domains. As expected, the Escherichia coli-derived glutathione $S$-transferase (GST)-POU domain fusion proteins containing either the wild-type Oct-1 POU domain or an Oct-1 POU domain carrying the Oct-2 homeo domain sequence (Oct-1/Ho2) display similar affinity for the $\left(\mathrm{OCTA}^{+}\right.$) TAATGARAT probe (cf. lanes 2 and 10). Furthermore, none of the 7 single amino acid replacements has an obvious effect on DNA binding either in the assay shown in Figure 2 (lanes 3-9) or at lower concentrations of the POU-domain protein (data not shown). In the assay for VP16-induced complex formation, however, the wild-type Oct-1 POU domain (lane 11), but not the Oct1/Ho2 POU domain (lane 19), formed the VP16-induced complex. Only 2 of the 7 individual amino acid replacements (lanes 12-18) affected VP16-induced complex formation. The replacement of glutamic acid with alanine in helix 1 (E22A) had a dramatic effect, resulting in little evident complex formation with VP16, whereas the replacement of methionine with leucine in helix 2 (M33L) had a twofold effect. Similar effects have also been observed by Pomerantz et al. (this issue).

To determine whether either one or both of the Oct-1 E22 and M33 residues are sufficient for VP16 to discriminate between the Oct-1 and Oct- 2 homeo domains, we asked whether VP16 can recognize an Oct-2 homeo domain carrying one or both of these residues. We replaced the Oct- 2 alanine residue at position 22 with a glutamic acid residue alone [Oct-1/Ho2(A22E)] or in combination with a methionine residue at position 33 [Oct-1/ Ho2(A22E + L33M)]. Figure 3 shows the effect of these 


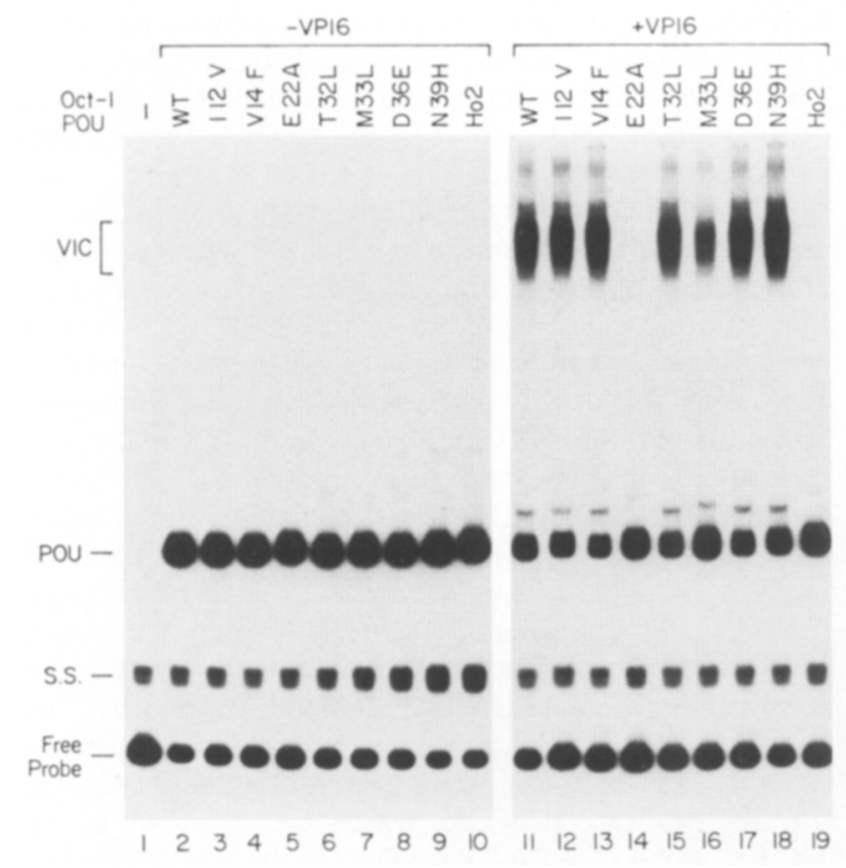

Figure 2. A glutamic acid residue at position 22 of the Oct-1 homeo domain is the key determinant for VP16 discrimination of the Oct- 1 and Oct- 2 homeo domains. An electrophoretic mobility retardation assay for VIC formation was performed for Oct-1 POU domain proteins containing individual residues exchanged for their Oct- 2 counterpart. The identity of the amino acid exchange for each POU domain is indicated at the top of each lane as described in the text (see also Fig. 1). Each variant Oct-1 POU domain protein was used in a reaction either in the absence (lanes 2-10) or presence (lanes 11-19) of GST-VP16 fusion protein and HCF. (Lane 1) (OCTA ${ }^{+}$|TAATGARAT probe alone. The positions of the free OCTA $^{+}$|TAATGARAT probe (Free Probe), denatured single-stranded probe (S.S.), Oct-1 POU domain/DNA complex (POU), and VP16-induced complexes (VIC) are shown at left.

two replacements on the ability of the Oct-2 homeo domain to associate with VP16. As expected, the replacements had little evident effect on binding to the (OCTA ${ }^{+}$TAATGARAT probe alone (lanes 1-5). Introduction of the single glutamic acid residue (A22E), however, resulted in $\sim 50 \%$ of the wild-type VP16 association activity, an effect also described by Pomerantz et al. (this issue), whereas the combination of the two exchanges (A22E + L33M) resulted in full activity (lanes 6-9). Thus, in this assay, only these two residues allow VP16 to discriminate between the human Oct-1 and Oct- 2 homeo domains. However, whereas the methionine residue at position 33 does not support effective association with VP16 in the absence of the glutamic acid residue at position 22 (Fig. 2, lane 14), the key glutamic acid residue is sufficient to support effective association of the Oct-2 homeo domain with VP16.

The key glutamic acid residue can be replaced by glutamine but not by aspartic acid with little effect on association with VP16 in vitro

To identify important features of the key glutamic acid residue at position 22 for association with VP16, we replaced this residue with a selected set of residues found naturally in other POU homeo domains. For comparison, Figure 4B shows the structure of 2 of the 3 amino acid replacements together with the structures of the Oct-1 glutamic acid and Oct-2 alanine residues. In one case, we replaced the glutamic acid residue with a glutamine residue (E22Q), as is found in the nematode unc86 POU homeo domain (Finney et al. 1988); glutamine is similar in size to glutamic acid but is uncharged owing to the replacement of the hydroxyl group for an amino group. In the other case, we replaced the glutamic acid residue with an aspartic acid residue (E22D), as is found in the murine Oct-11 POU homeo domain /Goldsborough et al. 1990); aspartic acid maintains the negative charge of glutamic acid but shortens the side chain. We also created a more drastic alteration by replacing the glutamic acid residue with a positively charged lysine residue (E22K), as is found in the murine Oct-3/4 POU homeo domain

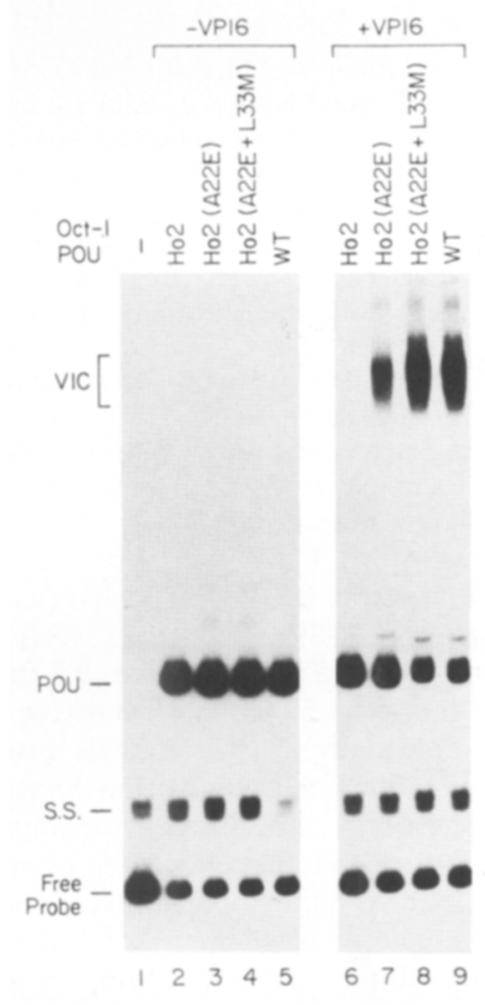

Figure 3. A single glutamic acid substitution for alanine 22 in helix 1 of the Oct-2 homeo domain supports VIC formation by the Oct-2 homeo domain. An electrophoretic mobility retardation assay for VIC formation was performed with wild-type Oct-1 POU domain carrying the Oct-2 homeo domain (Oct-1/ Ho2; lanes 2, 6), Oct-1/Ho2 carrying the glutamic acid for alanine exchange at position 22 [Oct-1/Ho2(A22E); lanes 3, 7], the double substitutions of alanine and leucine residues with glutamic acid and methionine [Oct-1/Ho2(A22E + L33M); lanes 4, 8 ], and wild-type Oct-1 POU domain protein (lanes 5, 9) either in the absence (lanes 2-5) or presence (lanes 6-9) of GSTVP16 6 C fusion protein and HCF. (Lane 1) Free $\left(\mathrm{OCTA}^{+}\right.$)TAATGARAT probe. The positions of the different electrophoretic species are as described in the legend to Fig. 2. 


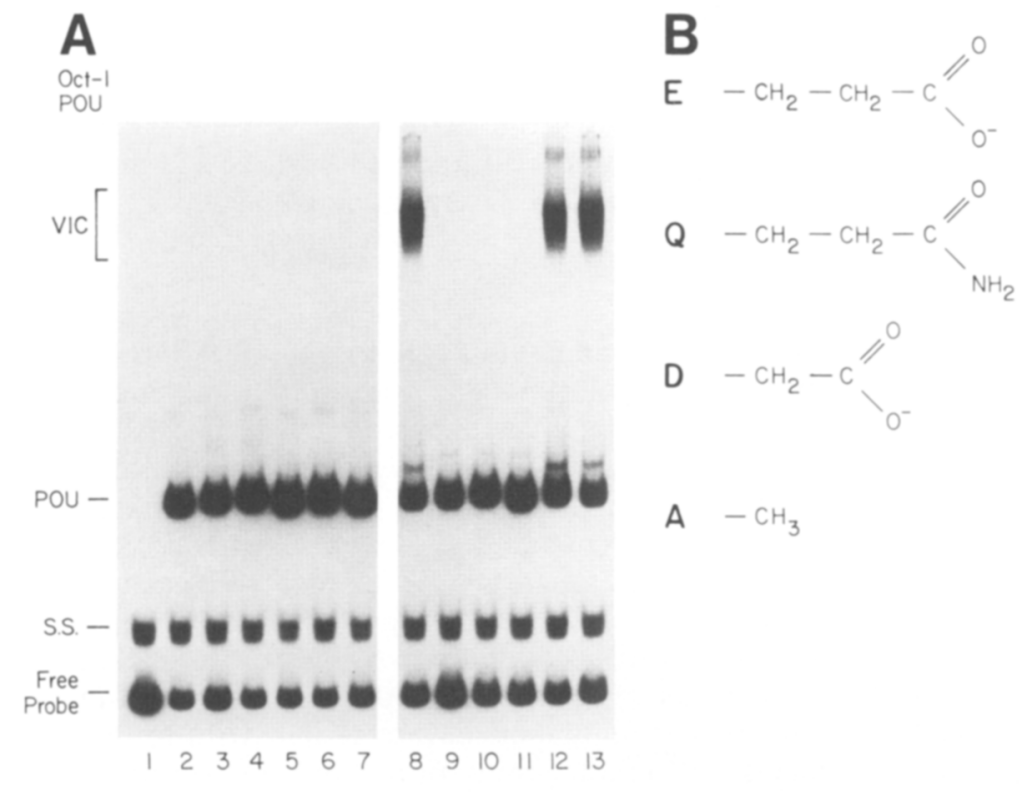

Figure 4. The glutamic acid residue at position 22 of the Oct-1 homeo domain can be replaced by glutamine, but not by aspartic acid or lysine, with little effect on association with VP16. (A) An electrophoretic mobility retardation assay for VIC formation was performed with wild-type Oct-1 POU domain (lanes 2, 7, 8, 13), or Oct-1 POU domain carrying the substitution of the glutamic acid residue at position 22 with alanine (E22A; lanes 3, 9), lysine (E22K; lanes 4, 10), aspartic acid (E22D; lanes 5, 11), or glutamine $(\mathrm{E} 22 \mathrm{Q}$; lanes 6,12$)$ in a reaction either in the absence (lanes 2-7) or presence (lanes 8-13) of GSTVP16 $\Delta C$ fusion protein and HCF. (Lane 1) Free OCTA $^{+} \mid$TAATGARAT probe; $(B)$ a schematic representation of the structures of the glutamic acid $(E)$, glutamine (Q), aspartic acid (D), and alanine (A) side chains.
(Okamoto et al. 1990; Rosner et al. 1990; Schöler et al. 1990).

Figure 4A shows the DNA-binding and VP16 association activity of these three glutamic acid replacements. None of these replacements adversely affected binding to the $\left(\mathrm{OCTA}^{+}\right.$|TAATGARAT probe (lanes 1-7), although the presence of an acidic (E or $D$; lanes 8,11 ), neutral (A

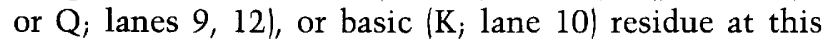
position affected the mobility of the POU domain-DNA complex slightly, probably owing to slight changes in the overall charge of the POU domain-DNA complex. In the assay for association with VP16, however, the Oct-1 POU domains carrying either the lysine or aspartic acid residues were inactive (lanes 10,11$)$. Thus, an acidic residue at this position is not sufficient for association with VP16 in vitro. Acidity is also not essential for association with VP16 because the Oct-1 POU domain carrying the glutamine residue at this position displays near wildtype activity (80\%) (lane 12). Thus, it is likely that hydrogen bonding or hydrophobic interactions with the glutamic acid residue are important for the interaction with VP16.

\section{A single amino acid difference is sufficient for selective positive control by the Oct-1 and Oct-2 homeo domains in the presence of VP16}

To measure the effects of selected amino acid swaps between the Oct-1 and Oct- 2 homeo domains on VP16dependent positive control, we took advantage of a recently developed in vivo transient expression assay in mouse cells (M. Cleary, S. Stern, M. Tanaka, and W. Herr, in prep.). VP16 does not activate transcription as effectively in mouse cells as in human cells, probably because the murine Oct-1 homeo domain differs from the human Oct-1 homeo domain at four positions (Goldsborough et al. 1990; Stepchenko 1992). As a result, when the human Oct-1 POU domain, but not an Oct-1 POU domain carrying the Oct-2 homeo domain, is expressed in murine NIH-3T3 cells, VP16 activation is stimulated $\sim 10$-fold, thus establishing that the Oct-1 homeo domain is involved in positive control in vivo ( $M$. Cleary, S. Stern, M. Tanaka, and W. Herr, in prep.).

This result is illustrated in Figure 5 (lanes 1-4, 9). Two

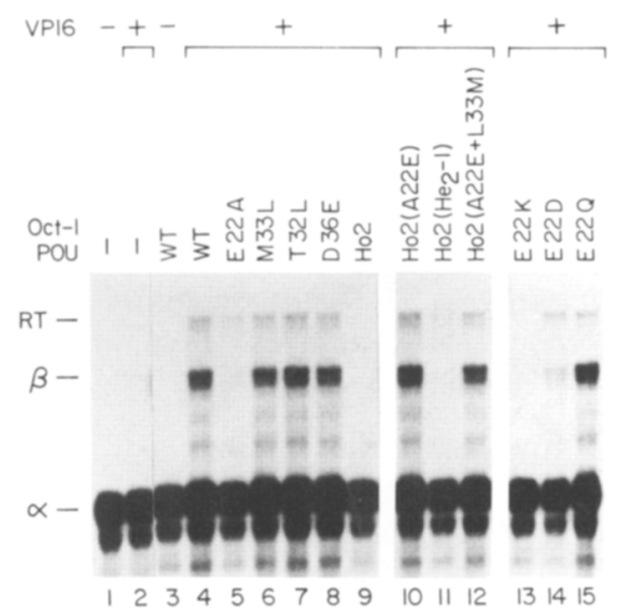

Figure 5. In vivo VP16-induced positive control by Oct-1 and Oct- 2 homeo domain chimeras and variants. The $\beta$-globin reporter plasmid, $\alpha$-globin internal reference plasmid, and wildtype or variant Oct-1 POU domain effector plasmid /as indicated at the top of each lane) were transfected into NIH-3T3 cells either in the absence (lanes 1,3) or presence (lanes 2, 4-15) of the VP16 expression plasmid, and RNA expression was analyzed by RNase protection as described in Materials and methods. Bands corresponding to correctly initiated $\alpha$-globin transcripts $(\alpha), \beta$-globin transcripts $(\beta)$, and incorrect readthrough (RT) transcripts are indicated. Samples were adjusted (no more than \pm two- to threefold) to equalize the $\alpha$-globin signal. 
reporter plasmids, one containing the human $\alpha$-globin transcription unit as an internal reference for transfection efficiency, and the other containing the human $\beta$-globin gene with multimerized VP16 responsive TAATGARAT motifs upstream of the transcriptional start site (see Materials and methods), were cotransfected into NIH-3T3 cells either in the presence or absence of effector constructs expressing Oct-1 POU domain derivatives and/or VP16. VP16 alone activated transcription of this $\beta$-globin reporter ineffectively (lanes $1,2)$, but in the presence of the human Oct-1 POU domain (lanes 3, 4) VP16 activation was elevated sevenfold (cf. lanes 2 and 4). No such stimulation was observed in the presence of the Oct-1 POU domain carrying the Oct-2 homeo domain (lane 91. This differential VP16induced activation provides a sensitive assay to measure the effects of amino acid swaps between the Oct-1 and Oct- 2 homeo domains on positive control in vivo.

To ensure that observed effects were not the result of poor expression or stability of one of the Oct-1 or Oct- 2 homeo domain derivatives, we monitored the levels of transient POU domain expression by preparing cell extracts from a portion of the transfected cells and performing an electrophoretic mobility retardation assay. This assay also measured the ability of the transiently expressed POU domain proteins to associate with VP16. The results showed that the various POU domain variants were expressed at similar levels and that even though they were produced in mammalian cells, their relative ability to associate with VP16 paralleled the VP16-association activities of the E. coli-produced proteins described above (data not shown).

Figure 5 shows that the positive control activities parallel the ability of the various Oct-1 homeo domain derivatives to associate with VP16, except that in the in vivo activation assay the effects of deleterious mutations are less disruptive than those in the in vitro assay. This quantitative difference may reflect different stringencies for Oct-1 association with VP16 in the two different assays. Of the four single amino acid replacements of Oct-1 for Oct-2 tested (lanes 5-8), only the replacement of E22A glutamic acid for alanine had a significant effect on VP16 activation (lane 5); the three individual exchanges in helix 2 (T32L, M33L, and D36E) had little, if any, effect on VP16 activation (lanes 6-8). Furthermore, the combination of all three Oct- 1 helix 2 residues in the context of the Oct-2 homeo domain only displays modest activity [Ho2( $\left.\mathrm{He}_{2}-1\right)$; lane 11], whereas transfer of the single critical Oct-1 glutamic acid residue (with or without the helix 2 methionine at position 33) to the Oct-2 homeo domain resulted in a wild-type VP16 response (cf. lanes 10 and 12 with lanes 4 and 9|. Consistent with the in vitro assays (see Fig. 4), lysine, but not glutamine, at position 22 of the Oct-1 homeo domain disrupts VP16induced positive control (lanes 13, 15). The aspartic acid residue at position 22 also disrupts VP16-induced positive control (lane 14), albeit to a lesser extent than the lysine (lane 13) or alanine (lane 5) substitutions, suggesting that it has a less deleterious effect on association with VP16 than these other mutations. Together, these results show that the activity of amino acid swaps or replacements for VIC assembly in vitro and VP16-induced activation in vivo correlate and show most significantly that a single amino acid exchange, A22E, is sufficient to transfer VP16-induced positive control from the Oct- 1 to the Oct- 2 homeo domain.

\section{Discussion}

There are now numerous instances in which DNA-binding domain mutations affect transcriptional activation without eliciting a corresponding defect in DNA binding. Examples include mutations in the DNA-binding domains of the glucocorticoid receptor (Hollenberg and Evans 1988; Schena et al. 1989), the yeast activator HAPl (Kim and Guarente 1989), MyoD (Weintraub et al. 1991; Davis and Weintraub 1992), and myogenin (Schwarz et al. 1992). Such positive control mutations are analogous to mutations within the $\lambda$ repressor DNAbinding domain that affect interactions with RNA polymerase to stimulate transcription but do not affect DNA binding (Guarente et al. 1982; Hawley and McClure 1983; Hochschild et al. 1983). The regulatory target affected by the positive control mutations in these eukaryotic activators has not been identified, however. Thus, VP16-induced positive control by Oct-1 represents a unique case where the effects of DNA-binding domain mutations on positive control can be correlated with the effects on association with the regulatory target / this report; M. Cleary, S. Stern, M. Tanaka, and W. Herr, in prep.).

The analysis of positive control mutations in Oct-1 has been aided greatly by the existence of its close relative Oct-2, which displays the same DNA-binding specificity but fails to respond to VP16 in vivo (M. Cleary, S. Stern, M. Tanaka, and W. Herr, in prep.) or to associate with VP16 in vitro (Gerster and Roeder 1988). The ability to compare and contrast Oct- 1 and Oct- 2 association with VP16 serves to elucidate how homeo domains can effect differential positive control while recognizing the same DNA sequence. The finding here that a single amino acid difference between two homeo domains, in this instance a glutamic acid for alanine difference, can direct the differential transcriptional response of two homeo domain proteins to a regulatory cofactor shows how simple it is to confer transcriptional activation specificity through selective homeo domain-cofactor interaction.

Although the glutamic acid residue at position 22 of the Oct-1 homeo domain is the key determinant by which VP16 discriminates between Oct- 1 and Oct-2, it is not the sole determinant for VP16 association with Oct1. In the accompanying study, Pomerantz et al. (this issue) show that at least three other positions within the Oct-1 homeo domain (K18, S19, and E30), positions that are identical between Oct- 1 and Oct-2, are as important for association with VP16 as the glutamic acid residue at position 22. The ability of single amino acid residues to influence protein association greatly suggests that they form part of a tight interface between the Oct-1 homeo 
domain and VP16. The interface with the discriminating glutamic acid residue at position 22 is likely to involve hydrophobic and/or hydrogen bonding interactions rather than ionic ones because it can be replaced by glutamine without any significant effect on association with VP16. This property may be unique to this position, however, because replacement of the glutamic acid residue at position 30 in helix 2 with glutamine has a dramatic effect on Oct-1 association with VP16 (Pomerantz et al. this issue).

The individual contributions of all seven amino-acid differences between the Oct- 1 and Oct- 2 homeo domains for association with VP16 identified here are consistent with our previous analysis (Stern et al. 1989), in which we reciprocally exchanged the three differing residues in helix 2 between Oct- 1 and Oct-2. The results of that study showed that VP16 association with Oct-l is dependent on one or more of the three Oct-1-specific residues in helix 2 but that these residues are not sufficient to induce Oct-2 association with VP16. Those results are explained by the disruptive effect of the M33L exchange in helix 2 and the critical importance of the glutamic acid residue in helix 1 .

In the previous study, however, the deleterious effect of exchanging helix 2 in Oct-1 for its Oct- 2 counterpart was greater $(90 \%$ loss of VP16-induced complex) than when the same helix 2 swap was retested in our current study (50\% loss; data not shown, but see Fig. 2; see also Pomerantz et al. this issue). The current comparison of the dramatic effect of the E22A exchange in helix 1 and the much smaller effect of the M33L exchange in helix 2 (Fig. 2) places less emphasis on helix 2 for selective association of Oct-1 with VP16 than was attributed previously to helix 2 (Stern et al. 1989). The quantitative difference between our previous and current studies is probably a result of the two different assays used to measure VP16-induced complex assembly. For example, in our previous study the relative levels of VP16-induced complex to Oct-1-binding activity were low owing to limiting levels of HCF activity in the reticulocyte lysates used to produce Oct-1 by in vitro translation, whereas in the current study we supplemented the binding reactions with partially purified HCF.

The current results suggest that the surface of the homeo domain/helix-turn-helix motif used for positive control by the Oct-1 homeo domain and $\lambda$ repressor DNA-binding domain differs. In $\lambda$ repressor, mutations in helix 2 but not helix 1 affect positive control (Hochschild et al. 1983; Bushman and Ptashne 1988; Bushman et al. 1989), whereas in Oct-1 primarily replacements in helix 1 have a dramatic effect on association with VP16 and positive control (see Figs. 2, 5); only one replacement in helix 2 has a dramatic effect on association with VP16 (Pomerantz et al., this issue). These results suggest that distinct surfaces of the homeo domain/helix-turn-helix motif can be involved in protein-protein interaction and positive control.

In Drosophila, homeo domain proteins form a large family of developmental regulatory proteins. In these proteins the homeo domain itself, even when very closely related, can direct different developmental programs (for review, see Hayashi and Scott 1990; see also Lin and McGinnis 1992). Homeo domain proteins seem especially suited to orchestrate such developmental regulatory pathways, because, as illustrated by the differential interaction of VP16 with the Oct- 1 and Oct- 2 homeo domains, very subtle changes-as subtle as a single amino acid change-can have dramatic effects on protein-protein interactions and transcriptional control.

\section{Materials and methods}

\section{Expression constructs}

Wild-type and variant GST-Oct-1 POU domain E. coli expression constructs, containing human Oct-1 residues $280-439$ (Sturm et al. 1988), were from a derivative of the vector pET11c.G.POU-1 (Aurora and Herr 1992) in which an f1 replication origin (Heitman et al. 1989) was inserted in the unique EcoRI site of pET11c (Studier et al. 1990) to produce antisense single-stranded DNA with respect to the Oct-1 POU domaincoding sequences. This pET1lc derivative is referred to as pET11c ori ${ }^{+}(-)$. Mutations were created by oligonucleotidedirected mutagenesis (Zoller and Smith 1983; Kunkel et al. 1987). For each mutation, a companion restriction site was either created or destroyed to serve as a marker for screening the mutations. The sequences created in the oligonucleotide-directed mutants are I12V, AACgTaCGT $\left(R s a I^{+}\right)$; V14F, CGTtTtGCC (HaeIII $\left.{ }^{-}\right)$; E22A, cTcGcGAAT $\left(\mathrm{NruI}^{+}\right)$; T32L, AGATCttaA (BglII $\left.{ }^{+}\right)$; M33L, ACatTaATT $\left(\right.$AseI $\left.^{+}\right)$; D36E, GCTGAaCAG $\left(B c l I^{-}\right) ; \mathrm{N} 39 \mathrm{H}$, CTCCATATG $\left(N d e \mathrm{I}^{+}\right) ; \mathrm{E} 22 \mathrm{~K}, \overline{\mathrm{CcTtaAG}}$ $\left(A f I \mathrm{II}^{+}\right)$; E22D, CcTcGAtA $\left.\left(\text {Taq }^{+}\right)^{+}\right)$E22Q, CcTgcAGA $\left(P_{s t \mathrm{I}^{+}}\right)$, where the uppercase letters represent the wild-type sequences and the lowercase letters represent mutations; the three letters in bold encode the missense mutation; and the created $1+1$ or destroyed $(-)$ restriction sites are underlined and identified in parentheses. Each mutation was verified by dideoxy DNA sequencing. The Oct- $1 / \mathrm{Ho} 2$ variant containing the Oct-2 homeo domain represents the wild-type Oct-1 POU domain with all seven of the Oct- 2 missense mutations described above. Like the Oct-1/Ho2 variant, the Oct-1/Ho2/A22E) and Oct-1/ Ho2(A22E + L33M) variants were made from wild-type Oct-1 by sequential mutagenesis incorporating the 6 or 5 Oct- 2 residues into the Oct-1 homeo domain, respectively. The GSTVP16 derivative GST-VP16 $\Delta$ C lacking the carboxy-terminal acidic activation domain (residues 413-490) was from the plasmid pET11c.G.VP16 $\Delta$ C, which will be described in detail elsewhere (J.-S. Lai and W. Herr, unpubl.).

The wild-type and variant Oct-1 POU domain expression constructs for transient expression in mammalian cells (pCG-Oct1-POU series) were constructed by transferring the Oct-1 POU domain-encoding sequences from the pET1lc.G.POU-1 constructs as an $\mathrm{XbaI}-\mathrm{BamHI}$ fragment into the unique $\mathrm{XbaI}$ and $B a m H I$ sites of the cytomegalovirus (CMV) promoter-containing expression vector pCG (Tanaka and Herr 1990). The pCGderived VP16 expression construct (pCG-VP16) likewise contains the VP16-coding sequences inserted between the pCG $X b a I$ and BamHI sites (A. Wilson and W. Herr, unpubl.).

\section{POU domain and VP16 expression and purification}

The wild-type and variant GST-Oct-1 POU domain and GSTVP16 $\Delta \mathrm{C}$ fusion proteins were expressed in E. coli BL21 (DE3) cells by using the T7 expression system (Studier et al. 1990). For optimal expression of soluble fusion proteins, typically $5 \mathrm{ml}$ of cells at $\mathrm{OD}_{600}=0.8-1.0$ were induced at $23^{\circ} \mathrm{C}$ overnight $\sim \sim 12$ 
hr) with isopropyl $\beta$-D-thiogalactopyranoside. The cells were then harvested by centrifugation and resuspended in a one-fifth volume of the culture medium with a buffer containing $25 \mathrm{~mm}$ HEPES-KOH (pH 7.9), $100 \mathrm{~mm} \mathrm{KCl,} \mathrm{20 \%} \mathrm{glycerol,} 0.2 \mathrm{~mm}$ PMSF, 2 mM EDTA, and 2 mM DTT. Following lysozyme treatment at $4^{\circ} \mathrm{C}, \mathrm{NP}-40$ (Sigma) was added to a final concentration of $0.1 \%$. The lysate was sonicated 10 times with 40 -sec pulses $(40 \%$ duty cycle $)$, and the insoluble portion was subsequently pelleted by centrifugation. To purify the GST fusion proteins, they were bound to glutathione-agarose (Sigma; $250 \mu \mathrm{l}$ of a $50 \%$ slurry per $1 \mathrm{ml}$ of extract) at $4^{\circ} \mathrm{C}$ for $1 \mathrm{hr}$, washed, and eluted with 2 aliquots of $120 \mu \mathrm{l}$ of $5 \mathrm{~mm}$ reduced glutathione (Sigma) in $50 \mathrm{~mm}$ Tris- $\mathrm{HCl}$ (pH8.0). Protein integrity, concentration, and purity were determined by Coomassie blue staining after SDSPAGE. Typically, $\sim 150 \mu \mathrm{g}$ of full-length fusion protein per $5 \mathrm{ml}$ of induced culture was obtained for the wild-type and variant GST-Oct-1 POU fusion proteins, whereas $\sim 10$-fold less fulllength protein was obtained for the GST-VP16 $\Delta \mathrm{C}$ fusion proteins. The full-length fusion protein was the major species $(60$ $90 \%$ ) present in each preparation; minor components were probably largely inactive truncation products of the full-length proteins.

\section{Electrophoretic mobility retardation assay for VIC formation}

The $\left(\mathrm{OCTA}^{+}\right)$TAATGARAT probe from the HSV ICP0 promoter (Stern and Herr 1991) was prepared by polymerase chain reaction (PCR) as described (Aurora and Herr 1992). Fractionated human HeLa cell-derived HCF devoid of Oct-1 was a kind gift of A. Wilson (Cold Spring Harbor Laboratory). Equivalent levels of purified GST-Oct-1 POU domain protein ( 1 ng) alone or with added GST-VP16 $\Delta$ C protein $(\sim 20 \mathrm{ng})$ and HCF fraction $\mid \sim 5 \mathrm{ng})$ were mixed in a $10 \mu$ l reaction [ $10 \mathrm{~mm}$ Tris- $\mathrm{HCl}(\mathrm{pH} 7.9)$, $60 \mathrm{~mm} \mathrm{KCl}, 1 \mathrm{~mm}$ DTT, $1 \mathrm{~mm}$ EDTA, 0.1\% NP-40, 2\% glycerol, $2 \%$ Ficoll- $400,10 \mathrm{ng}$ of sonicated salmon sperm DNA, $0.75 \mu \mathrm{g}$ of poly[d(I-C)], 3\% fetal bovine serum, $20,000 \mathrm{cpm}$ of (OCTA $^{+}$|TAATGARAT probe] for $30 \mathrm{~min}$ at $30^{\circ} \mathrm{C}$. After incubation, reactions were loaded directly onto a $4 \%$ polyacrylamide (39:1 acrylamide/bisacrylamide) gel in TGE $120 \mathrm{~mm}$ Tris- $\mathrm{HCl}, 200 \mathrm{~mm}$ glycine, $1 \mathrm{~mm}$ EDTA at $\mathrm{pH} 8.3$ ) and electrophoresed at $12 \mathrm{~V} / \mathrm{cm}$ for $\sim 2 \mathrm{hr}$. After electrophoresis, the gel was fixed, dried, and autoradiographed. Levels of VIC were quantitated on a Fuji BAS2000 PhosphorImager.

\section{Transient expression assay}

The in vivo human Oct-1-dependent VP16 activation assay in mouse cells will be described in detail elsewhere $(\mathrm{M}$. Cleary, $\mathrm{S}$. Stern, M. Tanaka, and W. Herr, in prep.). Briefly, $3 \times 10^{5} \mathrm{NIH}-$ $3 \mathrm{~T} 3$ cells were seeded onto $100-\mathrm{mm}$ dishes $24 \mathrm{hr}$ before transfection. The $\beta$-globin reporter plasmid $(4 \mu \mathrm{g})$, internal reference plasmid $\mathrm{p} \alpha$ 4X $(\mathrm{A}+\mathrm{C})(1 \mu \mathrm{g})$ (Tanaka and Herr 1990), pCG oct1-POU expression plasmid $(0.5 \mu \mathrm{g})$, pCG-VP16 plasmid $(0.5 \mu \mathrm{g})$, and pUC1 19 carrier DNA (up to $20 \mu \mathrm{g}$ of total DNA) were transfected by calcium phosphate coprecipitation. At $48 \mathrm{hr}$ posttransfection, the cells were harvested, resuspended in $200 \mu \mathrm{l}$ of $10 \mathrm{~mm}$ Tris- $\mathrm{HCl}(\mathrm{pH} 8.0), 150 \mathrm{mM} \mathrm{NaCl}$, and divided into two portions. To prepare cytoplasmic RNA, $180 \mu \mathrm{l}$ was used as described (Tanaka et al. 1988); and to prepare a "whole-cell nuclear" extract for DNA-binding assays $20 \mu \mathrm{l}$ was used as described (Tanaka et al. 1992). The $\beta$-globin reporter plasmid $\mathrm{pU} 2 / \beta \Delta^{36}$ contains divergent U2 small nuclear RNA (snRNA) and $\beta$-globin transcription units with a multimerized (OCTA ${ }^{-}$|TAATGARAT site from the HSV ICP4 promoter (M. Cleary, S. Sterm, M. Tanaka, and W. Herr, in prep.).

RNA expression was measured by RNase protection of radi- olabeled antisense RNA probes and electrophoresis of the resulting protected fragments through $6 \%$ denaturing polyacrylamide gels. The $\alpha 98$ probe and $\beta 143$ probe $(W$. Thomann and $W$. Herr, unpubl.) are protected by correctly initiated transcripts over 98 and 143 nucleotides, respectively. The radioactivity in the protected fragments was quantitated by measurement of the dried gels with a PhosphorImager (Fuji BAS2000), and the results were normalized to the level of the $\alpha$-globin internal reference expression. Similar results were obtained in three experiments. POU domain expression and VIC formation was assayed by electrophoretic mobility retardation, as described above, except that the transfected cell extract $(2 \mu \mathrm{l}$ out of $40 \mu \mathrm{l})$ containing transiently expressed POU domain and/or VP16 proteins was used in place of the GST-POU domain and GSTVP16 $\triangle \mathrm{C}$ proteins. These mouse cell extracts are limiting for HCF activity; therefore, they were assayed for POU domain expression without added human HCF and for VIC formation with added human HCF.

\section{Acknowledgments}

We are indebted to A. Wilson for fractionated human HCF and the pCG-VP16 expression plasmid; W. Thomann for the $\beta 143$ RNase protection probe; $C$. Desplan for the fd origin of replication; C. Pabo for the coordinates of the engrailed homeo domain/DNA cocrystal structure; M. Gilman, B. Matthews, A. Stenlund, and M. Tanaka for helpful discussions; J. Pomerantz, T. Kristie, and P. Sharp for communicating results prior to publication; N. Hernandez, A. Stenlund, and M. Tanaka for comments on the manuscript; J. Duffy and P. Renna for artwork; and J. Reader for typing the manuscript. These studies were supported by U.S. Public Health Service grant CA-13106 from the National Cancer Institute.

The publication costs of this article were defrayed in part by payment of page charges. This article must therefore be hereby marked "advertisement" in accordance with 18 USC section 1734 solely to indicate this fact.

\section{References}

Aurora, R. and W. Herr. 1992. Segments of the POU domain influence one another's DNA-binding specificity. Mol. Cell. Biol. 12: 455-467.

Bushman, F.D. and M. Ptashne. 1988. Turning $\lambda$ Cro into a transcriptional activator. Cell 54: 191-197.

Bushman, F.D., C. Shang, and M. Ptashne. 1989. A single glutamic acid residue plays a key role in the transcriptional activation function of lambda repressor. Cell 58: 1163-1171.

Davis, R.L. and H. Weintraub. 1992. Acquisition of myogenic specificity by replacement of three amino acid residues from MyoD into E12. Science 256: 1027-1030.

Finney, M., G. Ruvkun, and H.R. Horvitz. 1988. The C. elegans cell lineage and differentiation gene unc- 86 encodes a protein containing a homeo domain and extended sequence similarity to mammalian transcription factors. Cell 55: 757769.

Gerster, T. and R.G. Roeder. 1988. A herpesvirus transactivating protein interacts with transcription factor OTF-1 and other cellular proteins. Proc. Natl. Acad. Sci. 85: 6347-6351.

Goldsborough, A., A. Ashworth, and K. Willison. 1990. Cloning and sequencing of POU-boxes expressed in mouse testis. $\mathrm{Nu}$ cleic Acids Res. 18: 1634.

Guarente, L., J.S. Nye, A. Hochschild, and M. Ptashne. 1982. A mutant $\lambda$ repressor with a specific defect in its positive control function. Proc. Natl. Acad. Sci. 73: 2249-2253. 
Hawley, D.K. and W.R. McClure. 1983. The effect of a lambda repressor mutation on the activation of transcription initiation from the lambda $\mathrm{P}_{\mathrm{RM}}$ promoter. Cell 32: 327-333.

Hayashi, S. and M.P. Scott. 1990. What determines the specificity of action of Drosophila homeo domain proteins? Cell 63: $883-894$.

Heitman, J., J. Treisman, N.G. Davis, and M. Russel. 1989. Cassettes of the $\mathrm{f} 1$ intergenic region. Nucleic Acids Res. 17: 4413 .

Herr, W. 1992. Oct-1 and Oct-2: Differential transcriptional regulation by proteins that bind to the same DNA sequence. In Transcriptional regulation (ed. S. McKnight and K. Yamamotol, Cold Spring Harbor Laboratory Press, Cold Spring Harbor, New York. (In press.)

Herr, W., R.A. Sturm, R.G. Clerc, L.M. Corcoran, D. Baltimore, P.A. Sharp, H.A. Ingraham, M.G. Rosenfeld, M. Finney, G. Ruvkun, and H.R. Horvitz. 1988. The POU domain: A large conserved region in the mammalian pit-1, oct-1, oct-2, and Caenorhabiditis elegans unc-86 gene products. Genes \& Dev. 2: 1513-1516.

Hochschild, A., N. Irwin, and M. Ptashne. 1983. Repressor structure and the mechanism of positive control. Cell 32: 319-325.

Hollenberg, S.M. and R.M. Evans. 1988. Multiple and cooperative trans-activation domains of the human glucocorticoid receptor. Cell 55: 899-906.

Katan, M., A. Haigh, C.P. Verrijzer, P.C. van der Vliet, and P. O'Hare. 1990. Characterization of a cellular factor which interacts functionally with Oct- 1 in the assembly of a multicomponent transcription complex. Nucleic Acids Res. 18: $6871-6880$.

Kim, K.S. and L. Guarente. 1989. Mutations that alter transcriptional activation but not DNA binding in the zinc finger of yeast activator HAPI. Nature 342: 200-203.

Kissinger, C.R., B. Liu, E. Martin-Bianco, T.B. Kornberg, and C.O. Pabo. 1990. Crystal structure of an engrailed homeo domain-DNA complex at $2.8 \mathrm{~A}$ resolution: A framework for understanding homeo domain-DNA interactions. Cell 63: $579-590$.

Kristie, T.M. and P.A. Sharp. 1990. Interactions of the Oct-1 POU subdomains with specific DNA sequences and the HSV $\alpha$-trans-activator protein. Genes \& Dev. 4: 2383-2396.

Kristie, T.M., J.H. LeBowitz, and P.A. Sharp. 1989. The octamerbinding proteins from multi-protein-DNA complexes with the HSV $\alpha$ TIF regulatory protein. EMBO $I .8: 4229-4238$.

Kunkel, T.A., J.D. Roberts, and R.A. Zakour. 1987. Rapid and efficient site-specific mutagenesis without phenotypic selection. Methods Enzymol. 154: 367-382.

Lin, L. and W. McGinnis. 1992. Mapping functional specificity in the Dfd and Ubx homeo domains. Genes \& Dev. 6: 10711081.

Okamoto, K., H. Okazawa, A. Okuda, M. Sakai, M. Muramatsu, and H. Hamada. 1990. A novel octamer-binding transcription factor is differentially expressed in mouse embryonic cells. Cell 60: 461-472.

Pabo, C.O. and R.T. Sauer. 1992. Transcription factors: Structural families and principles of DNA recognition. Annu. Rev. Biochem. 61: 1053-1095.

Rosner, M.H., M.A. Vigano, K. Ozato, P.M. Timmons, F. Poirier, P.W.J. Rigby, and L. M. Staudt. 1990. A POU domain transcription factor in early stem cells and germ cells of the mammalian embryo. Nature 345: 686-692.

Schena, M., L.P. Freedman, and K.R. Yamamoto. 1989. Mutations in the glucocorticoid receptor zinc finger region that distinguish interdigitated DNA binding and transcriptional enhancement activities. Genes \& Dev. 3: 1590-1601.
Schöler, H.R., S. Ruppert, N. Suzuki, K. Chowdhury, and P. Gruss. 1990. New type of POU domain in germ line-specific protein Oct-4. Nature 344: 435-439.

Schwarz, J.J., T. Chakraborty, J. Martin, J. Zhou, and E.N. Olson. 1992. The basic region of myogenin cooperates with two transcription activation domains to induce muscle-specific transcription. Mol. Cell. Biol. 12: 266-275.

Staudt, L.M., H. Singh, R. Sen, T. Wirth, P.A. Sharp, and D. Baltimore. 1986. A lymphoid-specific protein binding to the octamer motif of immunoglobulin genes. Nature 323: 640643.

Stepchenko, A.G. 1992. The nucleotide sequence of mouse Oct-1 cDNA. Nucleic Acids Res. 20: 1419.

Stern, S. and W. Herr. 1991. The herpes simplex virus transactivator VP16 recognizes the Oct-1 homeo domain: Evidence for a homeo domain recognition subdomain. Genes \& Dev. 5: 2555-2566.

Stern, S., M. Tanaka, and W. Herr. 1989. The Oct-1 homeo domain directs formation of a multiprotein-DNA complex with the HSV trans-activator VP16. Nature 341: 624-630.

Studier, F.W., A.H. Rosenberg, J.J. Dunn, and J.W. Dubendorff. 1990. Use of T7 RNA polymerase to direct expression of cloned genes. Methods Enzymol. 185: 60-89.

Sturm R.A. and W. Herr. 1988. The POU domain is a bipartite DNA-binding structure. Nature 336: 601-604.

Sturm, R.A., G. Das, and W. Herr. 1988. The ubiquitous octamer-binding protein Oct-1 contains a POU domain with a homeo box subdomain. Genes \& Dev. 2: 1582-1599.

Tanaka, M. and W. Herr. 1990. Differential transcriptional activation by Oct-1 and Oct-2: Interdependent activation domains induce Oct-2 phosphorylation. Cell 60: 375-386.

Tanaka, M., U. Grossniklaus, W. Herr, and N. Hernandez. 1988. Activation of the U2 snRNA promoter by the octamer motif defines a new class of RNA polymerase II enhancer elements. Genes \& Dev. 2: 1764-1778.

Tanaka, M., J.-S. Lai, and W. Herr. 1992. Promoter-selective activation domains in Oct- 1 and Oct- 2 direct differential activation of an snRNA promoter and mRNA promoter. Cell 68: 755-767.

Weintraub, H., V.J. Dwarki, I. Verma, R. Davis, S. Hollenberg, L. Snider, A. Lassar, and S.J. Tapscott. 1991. Muscle-specific transcriptional activation by MyoD. Genes \& Dev. 5: 13771386.

Wolberger, C., A.K. Vershon, B. Liu, A.D. Johnson, and C.O. Pabo. 1991. Crystal structure of a MATa2 homeo domainoperator complex suggests a general model for homeo domain-DNA interactions. Cell 67: 517-528.

Xiao, P. and J.P. Capone. 1990. A cellular factor binds to the herpes simplex virus type 1 trans-activator Vmw65 and is required for Vmw65-dependent protein-DNA complex assembly with Oct-1. Mol. Cell. Biol. 10: 4974-4977.

Zoller, M.J. and M. Smith. 1983. Oligonucleotide-directed mutagenesis of DNA fragments cloned into M13 vectors. Meth ods Enzymol. 100: 468-500. 


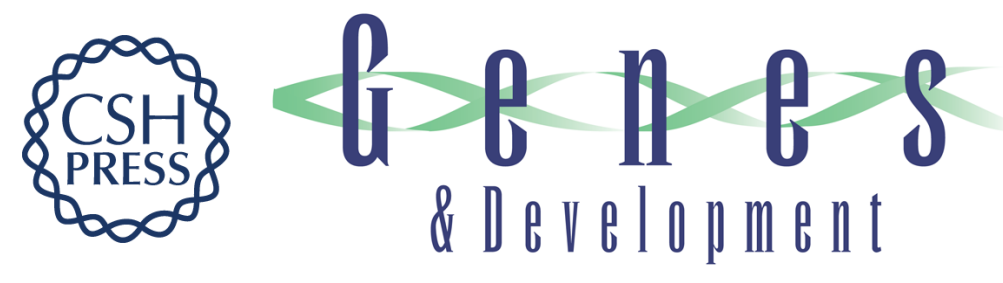

\section{A single amino acid exchange transfers VP16-induced positive control from the Oct-1 to the Oct-2 homeo domain.}

J S Lai, M A Cleary and W Herr

Genes Dev. 1992, 6:

Access the most recent version at doi:10.1101/gad.6.11.2058

References This article cites 41 articles, 13 of which can be accessed free at: http://genesdev.cshlp.org/content/6/11/2058.full.html\#ref-list-1

License

Email Alerting

Receive free email alerts when new articles cite this article - sign up in the box at the top Service right corner of the article or click here.

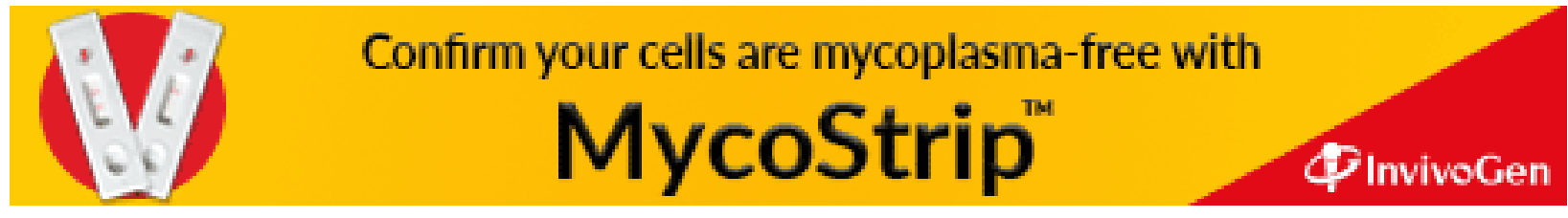

